\title{
Seasonality and household diets in Ethiopia
}

\author{
Kalle Hirvonen*, Alemayehu Seyoum Taffesse and Ibrahim Worku Hassen \\ International Food Policy Research Institute, C/O ILRI, Bole Sub-City, Kebele no 13, Box 5689, Addis Ababa, \\ Ethiopia
}

Submitted 11 June 2015: Final revision received 14 October 2015: Accepted 20 0ctober 2015: First published online 20 November 2015

\begin{abstract}
Objective: To revisit seasonality by assessing how household diets vary across agricultural seasons in rural and urban Ethiopia. The role of seasonality on the sources and intake of energy (per capita) and household dietary diversity score (HDDS) was analysed.

Design: The use of nationally representative household-level data collected each month over one year to study the seasonal changes in the sources and intake of energy and HDDS.

Setting: Eleven regions of Ethiopia, including rural and urban settings.

Subjects: Total of 27835 households were interviewed between July 2010 and July 2011 in all eleven regions of the country. On average each month saw 2300 household interviews, yielding nationally representative data for each calendar month.

Results: For rural households, the mean daily per capita energy intake was $10288 \mathrm{~kJ}$ $(2459 \mathrm{kcal})$ in February (post-harvest period) and lower in the lean season: $9703 \mathrm{~kJ}$ $(2319 \mathrm{kcal})$ in June $(P<0.05)$ and $9552 \mathrm{~kJ}(2283 \mathrm{kcal})$ in July $(P<0.001)$. HDDS for rural households was highest in February (6.73) and lowest in June $(5.98 ; P<0.001)$ but high again in July (6.57). Urban energy intake was also lower in the lean season but HDDS varied less by season. Considerable seasonal variation was also found in energy sources in rural areas, less so in urban areas.

Conclusions: Household diets in Ethiopia remain subjected to significant seasonal stress. HDDS and food security measured using energy intake do not always agree. Preferably, HDDS and energy intake data should be used together to assess food security.
\end{abstract}

Keywords

Seasonality

Energy intake

Food consumption Sub-Saharan Africa

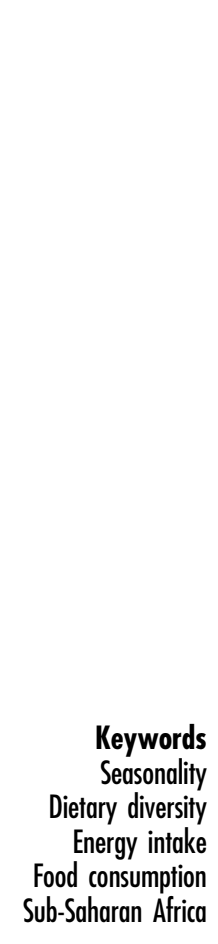

'As a dimension of poverty, seasonality is as glaringly obvious as it is still grossly neglected. Attempts to embed its recognition in professional mindsets, policy and practice have still a long way to go.'

\section{Robert Chambers ${ }^{(1)}$}

Seasonality in food consumption patterns in developing countries attracted considerable research attention in the 1990s and early 2000s. Nutritionists and other researchers documented substantial intra-annual fluctuations in children's and adults' anthropometric measures ${ }^{(2-6)}$. Economists found how various welfare indicators, such as consumption, incomes and prices, moved together with the agricultural seasons in many developing countries ${ }^{(7-10)}$. This body of research greatly improved our understanding of the seasonal stress that rural households in low-income countries face ${ }^{(11)}$. It also provided methodological insights into administering household surveys in developing country settings ${ }^{(12)}$. After these contributions were made, seasonality generally has received less research attention and has been largely neglected in policy arenas ${ }^{(13)}$. Kaminski et al. ${ }^{(14)}$ conjectured that this is partly due to the (mis)perception that local food markets are now well integrated in much of the developing world.

An emerging body of literature emphasizes the role of diet quality on various health and nutrition outcomes. Diet quality is typically measured through dietary diversity scores that count the number of food groups consumed in the previous $24 \mathrm{~h}$ to past $7 \mathrm{~d}^{(15-17)}$. Low diversity in diets is found to be associated with increased risk of chronic undernutrition among children ${ }^{(15,18)}$, Fe deficiency among children and adult women $^{(19,20)}$ and mortality from cancer and CVD ${ }^{(21)}$. Dietary diversity is also considered a good indicator of food security ${ }^{(22,23)}$. The importance of diet quality is now well acknowledged in the nutrition community ${ }^{(24,25)}$.

Despite this growing emphasis on diet quality in developing countries, limited evidence exists on how diet quality changes with the agricultural seasons. Most of the 
existing evidence comes from Burkina Faso. Savy et al. ${ }^{(26)}$ studied seasonality and dietary diversity in rural Burkina Faso using data from a sample of 550 women. Using a 9-point dietary diversity indicator, the authors found that an average woman in the sample consumed food from $3 \cdot 4$ food groups at the beginning of the lean season and from 3.8 food groups at the end of the lean season. This $10.5 \%$ increase in the average dietary diversity score during the lean season was attributed to changes in diets away from meat, poultry and fish to legumes, vegetables and milk. Becquey et al. ${ }^{(27)}$ studied changes in households' diets in the city of Ouagadougou during the lean and post-harvest seasons. Analysing data from a representative sample of 1056 urban households, they found that households consumed a diet that was less rich in terms of energy and micronutrients during the lean season compared with the post-harvest season. Arsenault et al. ${ }^{(28)}$ found similar evidence from rural Burkina Faso through an analysis of seasonal changes in nutrient intakes of 480 young children and their mothers. Elsewhere, Hassan et al. ${ }^{(29)}$ showed how food intakes tracked seasonal food availability in Bangladesh, while Bates et $a l{ }^{(30)}$ found that seasonality is an important determinant of micronutrient status among pregnant and lactating women in rural Gambia.

About $80 \%$ of the 85 million Ethiopians reside in rural areas and more than $80 \%$ of the employed people engage in agricultural activities ${ }^{(31,32)}$. Ethiopian farmers rely largely on rain-fed agriculture and therefore agricultural production in the country takes place in seasonal cycles. The main agricultural areas of the country have two rainy seasons. The small rainy season (belg) typically occurs between March and May and the main rainy season (meher) takes place between June and October. Meher is the most important season for agricultural production with more than $90 \%$ of the total crop production in the country taking place during this season ${ }^{(33)}$. Table 1 shows how the timing of the main harvesting season (following the meher rains) varies across the main regions, but occurs broadly between October and December.
The bulk of crop sales by farm households occur in the months of December, January and February. Livestock sales are more evenly scattered across the year. However, April typically the month just after the main Orthodox fasting season (see below) - records the largest sales.

In addition to weather cycles, religion plays a central role in shaping diets during a calendar year. This is particularly the case for the Orthodox Christians who comprise $44 \%$ of the Ethiopian population $^{(31)}$. The Orthodox Church year has a number of fasting periods. Lent is the longest fasting period spanning $55 \mathrm{~d}$ and usually taking place between February and April. During this period, devout Orthodox Christians follow a vegan diet by refraining from consuming meat or other animal products (e.g. milk, butter). Other shorter fasting periods occur in December-January (40 d) and August (16 d). For Muslims - who comprise $34 \%$ of the population ${ }^{(31)}$ Ramadan is the main fasting period and its timing varies across years. During Ramadan, Muslims abstain from eating and drinking between sunrise and sunset. The consumption of animal products is not restricted during Ramadan.

It is important to take these religious fasting events into account when analysing seasonality in the Ethiopian context. For example, when analysing the role of seasonality on diets in the following section, we expect that dietary diversity is lower during Lent. While only the followers of the Orthodox religion fast during Lent, the availability of animal products is limited during this period, especially in urban areas where many butcher shops close their businesses due to lack of demand. As Ramadan affects only the timing of meals, rather than restricting the content of the meals, it should not have a similar effect on dietary diversity. If anything, we expect that diets are more diverse during Ramadan, since the evening meals to break the fast generally consist of a wider variety of foods than is normally consumed ${ }^{(34)}$. However, we are not aware of studies that directly assess this question. The evidence on the impact of Ramadan on energy intake is inconclusive ${ }^{(34)}$.

Table 1 Ethiopian and Gregorian calendars, and main harvest and sales months by the main regions

\begin{tabular}{|c|c|c|c|c|c|}
\hline$\#$ & Ethiopian & Gregorian & Main (meher) harvest months & Main crop sales months & Main livestock sales month \\
\hline 1 & Meskerem & September & & & \\
\hline 2 & Tikimt & October & Tigray & & \\
\hline 3 & Hidar & November & Amhara, Oromiya, SNNP, Tigray & & \\
\hline 4 & Tahesas & December & Amhara, Oromiya, SNNP, Somali & Tigray & \\
\hline 5 & Tir & January & & Amhara, Oromiya, SNNP, Somali, Tigray & \\
\hline 6 & Yekatit & February & & Amhara, Oromiya, SNNP & Somali \\
\hline 7 & Megabit & March & & & \\
\hline 8 & Miazia & April & & & Amhara, Oromiya, SNNP, Tigray \\
\hline 9 & Ginbot & May & & & \\
\hline 10 & Sene & June & & & \\
\hline 11 & Hamle & July & & & \\
\hline 12 & Nehase & August & & & \\
\hline 13 & (Pagume) & (September) & & & \\
\hline
\end{tabular}

SNNP, Southern Nations, Nationalities, and Peoples' Region.

Harvest and sales times are based on own calculations from the Ethiopian Rural Socioeconomic Survey-2012 ${ }^{(53)}$ and the Feed the Future Survey $2013^{(54)}$. The Ethiopian calendar months typically begin during the first half of the Gregorian calendar month. Exact one-to-one mapping is therefore not possible. The Ethiopian calendar consists of thirteen months. The last month (Pagume) is only $5 \mathrm{~d}$ ( $6 \mathrm{~d}$ in leap years) and is therefore ignored in the analysis. 
The present paper revisits seasonality by assessing how the quantity and quality of diets vary across agricultural seasons in rural and urban Ethiopia. Using unique nationally representative household-level data for each month over one calendar year, we document seasonal fluctuations in household diets in terms of both the quantity of energy consumed and the number of different food groups from which households consumed food.

\section{Methods}

The primary data source used for the analysis described here is the Household Consumption and Expenditure Survey (HCES $)^{(35)}$. While not originally designed for nutrition analysis, the HCES data have been found to provide consistent information about various nutrition measures when compared with surveys based on $24 \mathrm{~h}$ recall $^{(36)}$. The Ethiopian HCES data are collected by the Ethiopian Central Statistical Agency and serve as the official source for poverty statistics in Ethiopia ${ }^{(37)}$. The latest HCES was conducted from 8 July 2010 to 7 July 2011. A novel feature of this round of the survey is that nationally representative data were collected in each month over one calendar year. Field teams of enumerators interviewed about 2300 households in each calendar month. A total of 27835 households were interviewed in the 12-month period. The survey covered all eleven regions of the country and included 864 rural and 1104 urban enumeration areas. The HCES did not cover the pastoralist communities in Afar (three zones) and Somali (six zones). The sampling began by stratifying the country into rural and urban areas. After that, the enumeration areas were selected using the probability-proportional-to-size approach where more populated units have a higher probability of being selected into the sample. The final household sample was then formed of households that were randomly selected from these enumeration areas. We use sampling weights, which are based on selection probabilities and provided by the Central Statistical Agency, to compute representative estimates for rural and urban areas of the country. In order to minimize recall error on consumption, each survey household was visited at least twice within one week. The HCES recorded dates using the Ethiopian calendar, which is different from the Gregorian calendar used in most Western countries. We map these Ethiopian calendar months onto the Gregorian calendar months (Table 1) and use the latter throughout the paper.

Household diets were assessed through an extensive consumption-expenditure module that considered 275 food items. The survey recorded the household's food consumption over the past $7 \mathrm{~d}$. Since each household was visited at least twice, the actual recall period in the consumption module was 3 to $4 \mathrm{~d}$. This alleviates concerns of recall bias in our energy intake and dietary diversity estimates.

We use daily per capita energy intake as our measure of diet quantity. For each food item, the survey recorded the quantity consumed which was then transformed into kilograms. Finally, the energy consumption measure was computed using the energy conversion factors reported in the Ethiopian food composition table ${ }^{(38)}$. The food composition table provides estimates for the number of kilocalories per $100 \mathrm{~g}$ for each food type.

The quality of diets is assessed using the household dietary diversity score (HDDS). Following Swindale and Bilinsky ${ }^{(39)}$, we categorized each of the 275 food items included in the questionnaire into twelve food groups: (i) cereals; (ii) roots and tubers; (iii) vegetables; (iv) fruits; (v) meat, poultry and offal; (vi) eggs; (vii) fish and seafood; (viii) pulses, legumes and nuts; (ix) milk and milk products; (x) oil and fats; (xi) sugar and honey; and (xii) miscellaneous foods. After this, the HDDS was computed by summing up the food groups from which the household consumed food items. A household that consumed an item from each food group receives the maximum score of 12 . In contrast, a household that consumed only cereals and pulses over the $7 \mathrm{~d}$ period, for example, obtains an HDDS of 2. The HDDS is constructed so that a higher dietary diversity score implies that the household consumes a diet that has more diversity in terms of foods consumed and, by extension, in terms of macro- and micronutrients.

The HCES did not collect information about the household's involvement in fasting activities in the past $7 \mathrm{~d}$. We therefore settle for matching the dates of the main fasting periods with the HCES data. We return to this limitation of our study in the Discussion section. In the survey period, Lent started on 28 February (21 Yekatit) and ended on 16 April (8 Miazia). Ramadan started on 1 August (25 Hamle) and ended on 29 August (23 Nehase).

\section{Results}

Figure 1 plots the mean per capita daily energy intake for each month. In line with the findings of Berhane et al. ${ }^{(40)}$ and the Central Statistical Agency ${ }^{(35)}$, rural households are seen to enjoy better diets in terms of energy consumed. The mean daily energy consumption for rural households was $10226 \mathrm{~kJ}$ (2444 kcal) per capita, whereas urban households consumed, on average, $9569 \mathrm{~kJ}$ (2287 kcal) per capita. This difference in average energy consumption likely reflects higher average energy requirements in rural areas partly due to the demands of more physical labour ${ }^{(41)}$. More expensive sources of energy in urban areas may also play a role in these different energy consumption patterns (I Worku, M Dereje, G Berhane, B Minten and AS Taffesse, unpublished results).

Looking at the seasonal patterns reveals that rural households maintained a similar level of energy consumption throughout the year, except during the lean season (June-July) when energy intake dropped sharply. Compared with February (10 288 kJ (2459 kcal)), energy intake was about 6-7\% lower in June (9703 kJ (2319 kcal); 


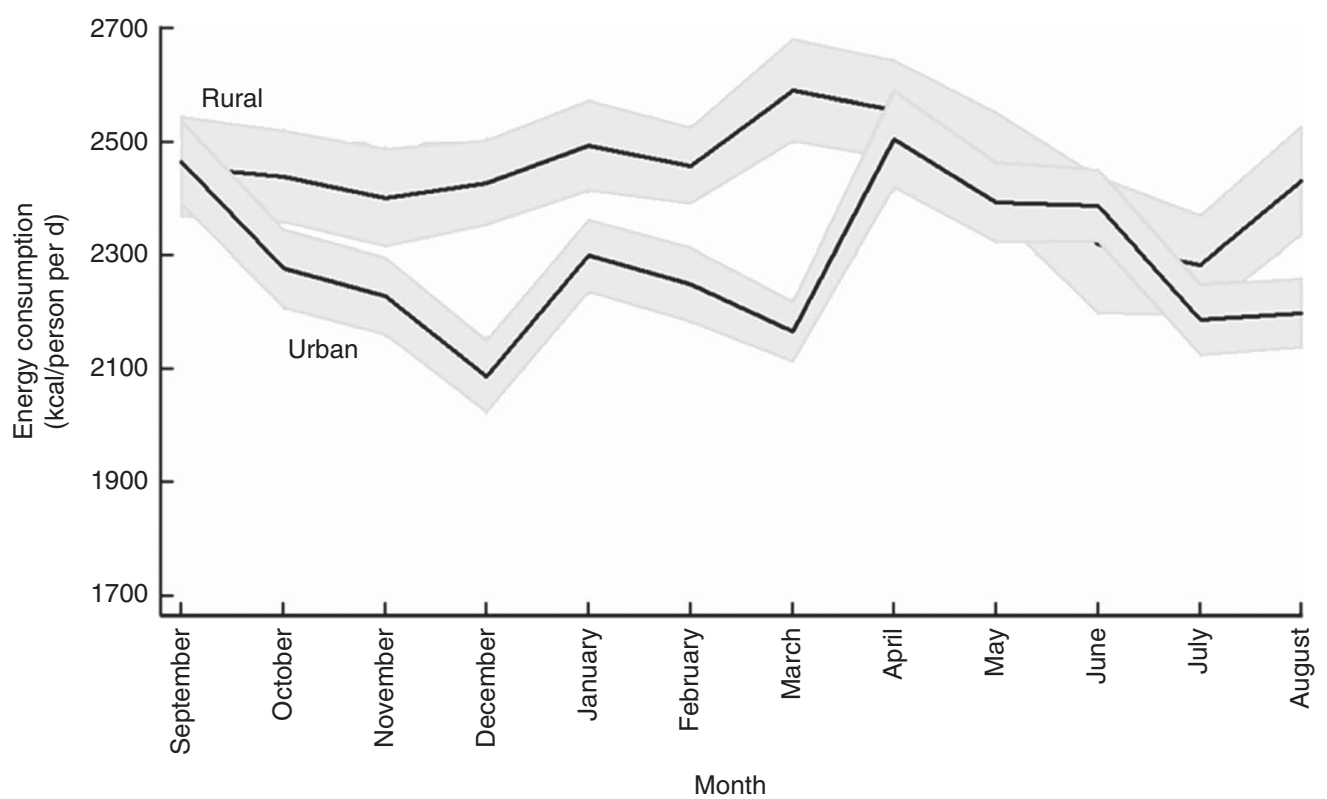

Fig. 1 Seasonal patterns in mean daily per capita energy intake, by rural/urban setting, among 27835 households from eleven regions of Ethiopia; Household Consumption and Expenditure Survey, 2010/11 ${ }^{(35)}$. The vertical axis measures daily per capita energy consumption of households in kilocalories $(1 \mathrm{kcal}=4.184 \mathrm{~kJ})$. The solid line gives the mean for each calendar month and the grey area represents the $95 \%$ confidence interval

$P<0.05)$ and July $(9552 \mathrm{~kJ} \quad(2283 \mathrm{kcal}) ; \quad P<0.001)$. Average energy intake for the urban sample showed more volatility and seemed to be more affected by the Orthodox fasting events. During the two main fasting periods, December (8732 kJ (2087 kcal)) and March $(9063 \mathrm{~kJ}$ $(2166 \mathrm{kcal}))$, energy consumption in urban areas fell sharply but rose quickly once the fasting period was over. Similarly to rural households, energy consumption among urban households was low during the lean season (June: $9150 \mathrm{~kJ}(2187 \mathrm{kcal}))$. Fasting was not associated with a similar reduction in energy consumption in rural areas, possibly because animal-source foods contributed little to overall energy intake (see Fig. 3).

Figure 2 shows how the number of food groups from which food is consumed varied across the calendar year. Here we see that urban households consumed a more diverse diet than their rural counterparts. The mean number of food groups from which food was consumed by urban households was 7.7 across the twelve months, while the corresponding figure for rural households was 6.4 out of the maximum of twelve food groups. For both rural and urban households, the two fasting months, December (rural: 6.19; urban: 7.53) and March (rural: 6.36; urban: 7.35), were associated with a drop in the dietary diversity score. HDDS for rural households was highest in February (6.73) and lowest in June (5.98; $P<0.001)$ but interestingly was at post-harvest levels in July (6.57). Urban households' HDDS was somewhat less affected by the scarcity of food in the lean season: HDDS was highest in July (8.10) when HDDS was $5.2 \%$ above the monthly mean value $(P<0.001)$.
Figure 3 provides the percentage share of average energy intake from non-cereal sources for each month. Cereals (the omitted food category in Fig. 3) were the main source of energy for both rural and urban households. On average, about $60 \%$ of the energy consumed by households came from cereals, with little difference between urban and rural households. However, there was considerable seasonal variation in the energy sources in rural areas, less so in urban areas. In the post-harvest period, March and April, 44\% of energy consumed by rural households originated from non-cereal sources. In the lean season, cereals became more important. The share of energy coming from non-cereals dropped below $40 \%$ in the lean season, with only $30 \%$ of energy coming from non-cereal sources in June.

Roots and tubers were the second most important source for energy for rural households. Throughout the year, about 15 to $20 \%$ of energy came from this food group. However, the consumption of roots and tubers plummeted dramatically in the lean season. The share of energy consumed coming from roots and tubers dropped to $9 \%$ in May and then to $0.2 \%$ in June, while recovering back to $9 \%$ in July. For urban households, roots and tubers constituted a less important source of energy, with only $4 \%$ of energy coming from this source, on average.

Pulses, legumes and nuts contributed about $8 \%$ to the overall energy intake in both areas. The share increased to $14 \%$ in June - the month in which rural households stopped consuming roots and tubers. Animal-source foods (meat, poultry, fish, and milk and milk products) contributed little to the overall energy intake, $1.7 \%$ for 


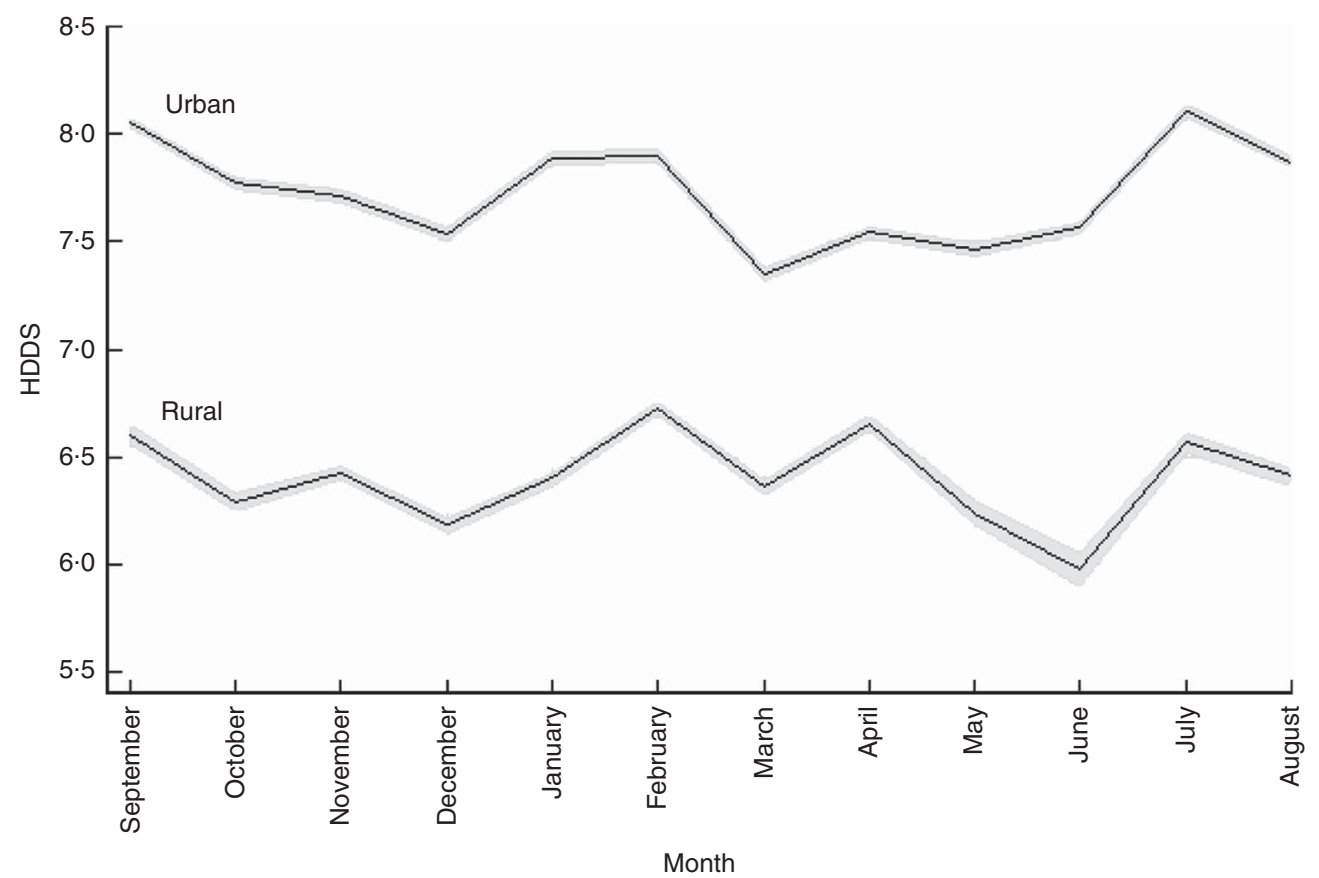

Fig. 2 Seasonal patterns in mean household dietary diversity score (HDDS), by rural/urban setting, among 27835 households from eleven regions of Ethiopia; Household Consumption and Expenditure Survey, 2010/11 ${ }^{(35)}$. The vertical axis measures the number of food groups consumed by households. The solid line gives the mean for each calendar month and the grey area represents the $95 \%$ confidence interval

rural households and $3.0 \%$ for urban households, on average. As expected, the shares fell in December (rural: 1.5\%; urban: $2 \cdot 0 \%$ ) and March (rural: $1.1 \%$; urban: $1.5 \%$ ), the main Orthodox fasting months. Fruits and vegetables were another unimportant source of energy (rural: 1.9\%; urban: $3 \cdot 3 \%$ ). The 'other sources' category includes oils and fats, sugar and honey, and miscellaneous items. Oils and fats were a particularly important source of energy for the urban households with $10 \cdot 5 \%$ of energy coming from this source, on average (rural: $3 \cdot 1 \%$ ).

\section{Discussion}

Our national-level estimates confirm the results from previous studies: Ethiopian diets are characterized by low energy intakes and are monotonous in terms of dietary diversity $^{(42,43)}$. Low energy intakes and dietary diversity are likely to have serious nutritional implications. For example, recent literature shows how dietary diversity is positively correlated with micronutrient intake and density ${ }^{(44-46)}$ and negatively with stunting rates, even after controlling for various socioeconomic factors ${ }^{(15)}$. While child stunting and underweight rates have been falling rapidly in Ethiopia over the past decade $^{(42)}$ they remain high by regional and international standards. Together with investments in sanitation (D Headey, unpublished results), improving diet quantity and quality are likely to be important in ensuring that these positive trends continue in the future.
The seasonal analysis of diets reveals that rural households consume extremely monotonous diets in June consisting mainly of cereals and pulses, legumes and nuts. Of note is that these food items can be stored for several months after the harvest. In July and August, roots and tubers feature more dominantly in the diet again, possibly due the fact that these foods require a shorter growing time and therefore become available earlier than, for example, most cereals. However, overall energy intake remains low during these months, implying that the content of the household food basket becomes more diversified during this period, while the quantities consumed decrease.

An interesting finding of the present study is that the composition of the diet varies across the seasons. As a result, the dietary diversity score is relatively high at the height of the lean season - a period characterized by lowest energy intake in rural areas. Previous literature has considered dietary diversity as a good indicator of food security ${ }^{(22,39)}$. This decoupling of the diet quantity and diversity measures observed in the lean season suggests that the seasonal validity of this indicator cannot be taken for granted. Indeed, at least in Ethiopia and other similar contexts, researchers should, as a matter of routine, measure food security through different indicators, not only through the dietary diversity score.

The present study has limitations. First, the HCES data permit us to assess diets only at the household level. The consequences of seasonality can be greater if specific groups such as children, girls or women are more affected by it. Therefore, one area of further research would be to 

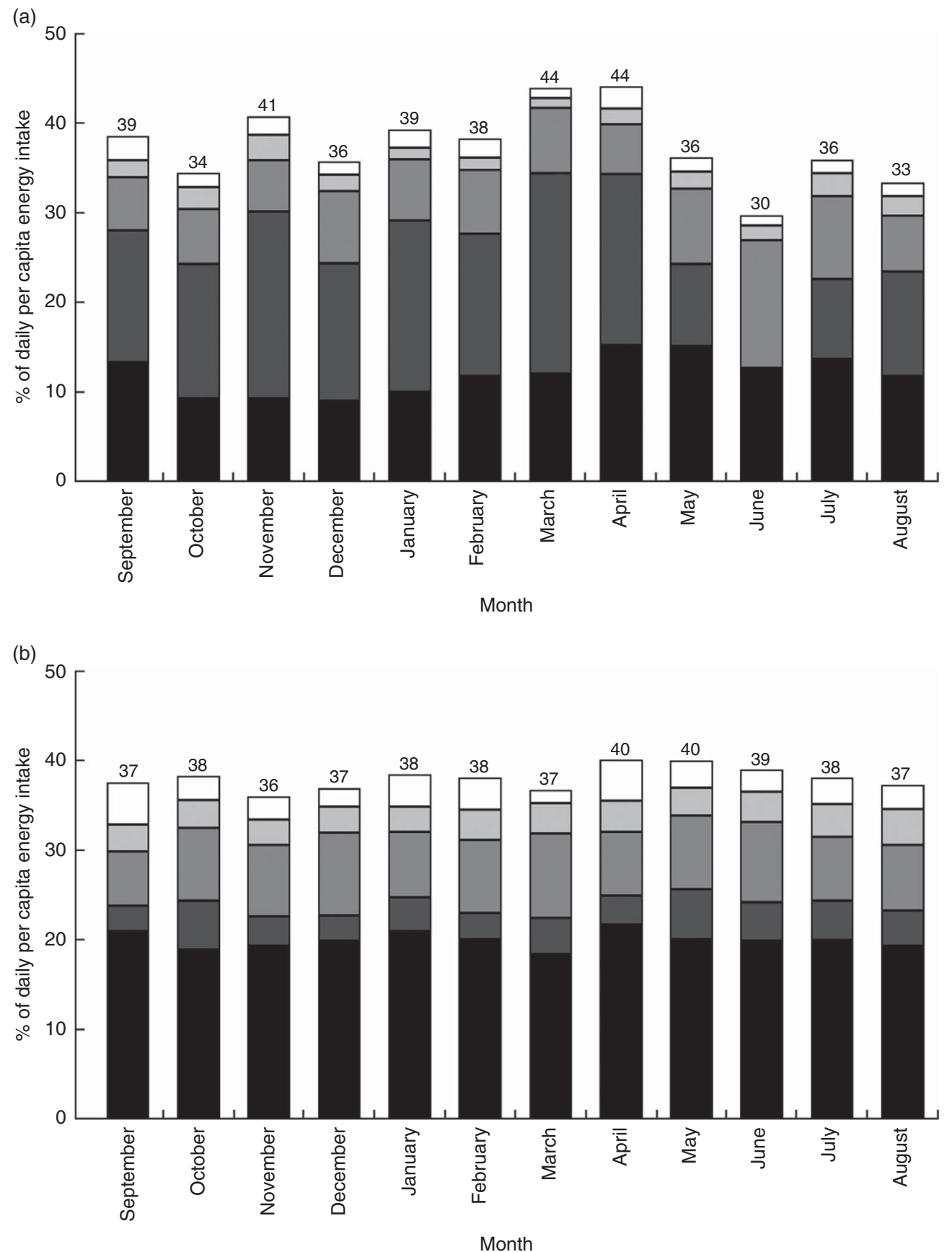

Fig. 3 Percentage share of daily per capita energy intake from non-cereal sources by month, by (a) rural and (b) urban setting, among 27835 households from eleven regions of Ethiopia; Household Consumption and Expenditure Survey, 2010/11 (35). The vertical axis measures the percentage of daily per capita energy in each month coming from different food groups: $\square$, other sources; $\square$, roots and tubers; $\square$, pulses, legumes and nuts; $\square$, fruits and vegetables; $\square$, animal-source foods. The number at the top of each bar gives the percentage of energy coming from non-cereal foods. Cereal foods constitute the omitted category; the percentage of energy coming from cereals each month can be obtained by subtracting the number at the top of the bar from 100 . The 'other sources' category includes oils and fats, sugar and honey, and miscellaneous items

explore intra-household dietary diversity across seasons. Second, we find suggestive evidence that urban diets are more affected by religious fasting events than by seasonality. However, lack of detailed information about fasting activities undertaken by the households does not allow us to explore this further. Therefore, the role of religious fasting on diets should be assessed in the future with more detailed data on this matter. Third, while dietary diversity is considered to be a good indicator for micro- and macronutrient intakes ${ }^{(17,45,46)}$, it would be important to directly assess seasonal changes in protein, Fe and vitamin intakes. Fourth, access to markets could be 
an important mitigating factor in reducing the role of seasonality on diets. Our results for the urban sample allude to this but more rigorous evidence is needed. Emerging literature highlights the role of market access for better diets $^{(43,47,48)}$ but so far little evidence exists on how market access interacts with seasonality.

Finally, the study findings contribute to the growing literature that attempts to understand the role of agriculture in improving food and nutrition security in low-income countries. However, the evidence of the effectiveness of agricultural interventions on nutrition outcomes remains sparse ${ }^{(49-51)}$. Limited attention to seasonality in this research programme may well be one reason for this. Indeed, while agricultural investments typically focus on the main agricultural season, a large body of literature suggests that seasonal hunger is a major contributor to malnutrition in low-income countries ${ }^{(52)}$. Therefore, agricultural investments that improve access to foods in the lean season may be more effective in addressing food and nutrition security than those that only target the harvest season. Further research is needed to confirm the validity of these ideas.

\section{Acknowledgements}

Acknowledgements: The authors thank Derek Headey and Helina Tilahun for useful comments. Financial support: Funding for this work was received through the Feed-theFuture project funded by the US Agency for International Development. The funder had no role in the design, analysis or writing of this article. Conflict of interest: The authors do not report any conflicts of interest. Authorship: K.H. and I.W.H. conducted the literature search. I.W.H. prepared the data. K.H. analysed the data. K.H. and A.S.T. wrote the manuscript. All authors approved the final version of the paper. Ethics of human subject participation: The study was conducted using secondary data collected by the Central Statistical Agency of Ethiopia. The data set had no personal identifiers.

\section{References}

1. Chambers R (2012) Foreword. In Seasonality, Rural Livelihoods and Development, pp. vx [S Devereux, R Sabates-Wheeler and R Longhurst, editors]. London and New York: Routledge.

2. Ferro-Luzzi A, Morris SS, Taffesse S et al. (2001) Seasonal Undernutrition in Rural Ethiopia, IFPRI Research Report no. 18. Washington, DC, Rome and Addis Ababa: International Food Policy Research Institute and Istituto Nazionale della Nutrizione in collaboration with Ethiopian Health and Nutrition Research Institute.

3. Maleta K, Virtanen S, Espo M et al. (2003) Seasonality of growth and the relationship between weight and height gain in children under three years of age in rural Malawi. Acta Paediatr 92 , 491-497.

4. Alemu T \& Lindtjørn B (1995) Physical activity, illness and nutritional status among adults in a rural Ethiopian community. Int J Epidemiol 24, 977-983.
5. Leonard WR (1991) Household-level strategies for protecting children from seasonal food scarcity. Soc Sci Med 33, 1127-1133.

6. Panter-Brick C (1997) Seasonal growth patterns in rural Nepali children. Ann Hum Biol 24, 1-18.

7. Dercon S \& Krishnan P (2000) Vulnerability, seasonality and poverty in Ethiopia. J Dev Stud 36, 25-53.

8. Dostie B, Haggblade S \& Randriamamonjy J (2002) Seasonal poverty in Madagascar: magnitude and solutions. Food Policy 27, 493-518.

9. Behrman JR \& Deolalikar AB (1989) Agricultural wages in India: the role of health, nutrition, and seasonality. In Seasonal Variability in Third World Agriculture: The Consequences for Food Security, pp. 107-117 [DE Sahn, editor]. Baltimore, MD: Johns Hopkins University Press.

10. Sahn DE \& Delgado C (1989) The nature and implications for market interventions of seasonal food price variability. In Seasonal Variability in Third World Agriculture: The Consequences for Food Security, pp. 179-195 [DE Sahn, editor]. Baltimore, MD: Johns Hopkins University Press.

11. Sahn DE (editor) (1989) Seasonal Variability in Third World Agriculture: The Consequences for Food Security. London: IFPRI \& Johns Hopkins University Press.

12. Deaton A \& Grosh M (2000) Consumption. In Designing Household Survey Questionaires for Developing Countries: Lessons from 15 Years of Living Standards Measurement Study, vol. 1, pp. 91-133 [M Grosh and P Glewwe, editors]. Washington, DC: World Bank.

13. Devereux S, Sabates-Wheeler R \& Longhurst R (editors) (2012) Seasonality, Rural Livelihoods and Development. London and New York: Routledge.

14. Kaminski J, Christiaensen L \& Gilbert CL (2014) The End of Seasonality? New Insights from Sub-Sabaran Africa. Policy Research Working Paper no. 6907. Washington, DC: World Bank.

15. Arimond M \& Ruel MT (2004) Dietary diversity is associated with child nutritional status: evidence from 11 demographic and health surveys. J Nutr 134, 2579-2585.

16. Savy M, Martin-Prével Y, Sawadogo P et al. (2005) Use of variety/diversity scores for diet quality measurement: relation with nutritional status of women in a rural area in Burkina Faso. Eur J Clin Nutr 59, 703-716.

17. Moursi MM, Arimond M, Dewey KG et al. (2008) Dietary diversity is a good predictor of the micronutrient density of the diet of 6- to 23-month-old children in Madagascar. J Nutr 138, 2448-2453.

18. Mallard SR, Houghton LA, Filteau S et al. (2014) Dietary diversity at 6 months of age is associated with subsequent growth and mediates the effect of maternal education on infant growth in urban Zambia. J Nutr 144, 1818-1825.

19. Tatala S, Svanberg U \& Mduma B (1998) Low dietary iron availability is a major cause of anemia: a nutrition survey in the Lindi District of Tanzania. Am J Clin Nutr 68, 171-178.

20. Bhargava A, Bouis HE \& Scrimshaw NS (2001) Dietary intakes and socioeconomic factors are associated with the hemoglobin concentration of Bangladeshi women. $J$ Nutr 131, 758-764.

21. Kant AK, Schatzkin A \& Ziegler RG (1995) Dietary diversity and subsequent cause-specific mortality in the NHANES I epidemiologic follow-up study. J Am Coll Nutr 14, 233-238.

22. Hoddinott J \& Yohannes Y (2002) Dietary Diversity as a Food Security Indicator. Washington, DC: International Food Policy Research Institute.

23. Ruel MT (2003) Operationalizing dietary diversity: a review of measurement issues and research priorities. J Nutr 133, 11 Suppl. 2, 3911S-3926S.

24. US Agency for International Development (2014) USAID's 2014-2025 Multi-Sectoral Nutrition Strategy. Washington, DC: USAID. 
25. World Health Organization \& UNICEF (2003) Global Strategy for Infant and Young Child Feeding. Geneva: WHO.

26. Savy M, Martin-Prével Y, Traissac P et al. (2006) Dietary diversity scores and nutritional status of women change during the seasonal food shortage in rural Burkina Faso. J Nutr 136, 2625-2632.

27. Becquey E, Delpeuch F, Konaté AM et al. (2012) Seasonality of the dietary dimension of household food security in urban Burkina Faso. Br J Nutr 107, 1860-1870.

28. Arsenault JE, Nikiema L, Allemand P et al. (2014) Seasonal differences in food and nutrient intakes among young children and their mothers in rural Burkina Faso. J Nutr Sci $\mathbf{3}$, e 55.

29. Hassan N, Huda N \& Ahmad K (1985) Seasonal patterns of food intake in rural Bangladesh: its impact on nutritional status. Ecol Food Nutr 17, 175-186.

30. Bates CJ, Prentice AM \& Paul A (1994) Seasonal variations in vitamins A, C, riboflavin and folate intakes and status of pregnant and lactating women in a rural Gambian community: some possible implications. Eur J Clin Nutr 48, 660-668.

31. Central Statistical Agency of Ethiopia (2010) Population and Housing Census Report-Country - 2007. Addis Ababa: CSA.

32. Central Statistical Agency of Ethiopia (2006) Report on the 2005 National Labour Force Survey. Statistical Bulletin no. 365. Addis Ababa: CSA.

33. Taffesse AS, Dorosh P \& Gemessa SA (2012) Crop production in Ethiopia. In Food and Agriculture in Ethiopia, pp. 53-83 [P Dorosh and S Rashid, editors]. Philadelphia, PA: University of Pennsylvania Press.

34. Trepanowski JF \& Bloomer RJ (2010) The impact of religious fasting on human health. Nutr J 9, 57.

35. Central Statistical Agency of Ethiopia (2012) Household Consumption and Expenditure (HCE) Survey 2010/11: Analytical Report. Statistical Bulletin no. 563. Addis Ababa: CSA.

36. Fiedler JL (2013) Towards overcoming the food consumption information gap: strengthening household consumption and expenditures surveys for food and nutrition policymaking. Global Food Secur 2, 56-63.

37. Ministry of Finance and Economic Development (2013) Development and Poverty in Ethiopia 1995/96-2010/11. Addis Ababa: MoFED.

38. Ethiopian Health and Nutrition Research Institute (1968-1997) Food Composition Table for Use in Ethiopia Part III. Addis Ababa: EHNRI.

39. Swindale A \& Bilinsky P (2006) Household Dietary Diversity Score (HDDS) for Measurement of Household Food Access: Indicator Guide. Washington, DC: Food and Nutrition Technical Assistance Project, Academy for Educational Development.

40. Berhane G, McBride L, Hirfrot KT et al. (2012) Patterns in foodgrain consumption and calorie intake. In Food and Agriculture in Ethiopia, pp. 190-216 [P Dorosh and S Rashid, editors]. Philadelphia, PA: University of Pennsylvania Press.
41. Popkin BM (1999) Urbanization, lifestyle changes and the nutrition transition. World Dev 27, 1905-1916.

42. Headey D (2014) An Analysis of Trends and Determinants of Child Undernutrition in Ethiopia, 2000-2011. Ethiopia Strategy Support Program (ESSP) Working Paper no. 70. Washington, DC and Addis Ababa: International Food Policy Research Institute, IFPRI-ESSP Addis Ababa and Ethiopian Development Research Institute.

43. Hirvonen K \& Hoddinott J (2014) Agricultural Production and Children's Diets: Evidence from Rural Ethiopia. Ethiopia Strategy Support Program (ESSP) Working Paper no. 69. Washington, DC and Addis Ababa: International Food Policy Research Institute, IFPRI-ESSP Addis Ababa and Ethiopian Development Research Institute.

44. Daniels M, Adair L, Popkin B et al. (2009) Dietary diversity scores can be improved through the use of portion requirements: an analysis in young Filipino children. Eur J Clin Nutr 63, 199-208.

45. Kennedy GL, Pedro MR, Seghieri C et al. (2007) Dietary diversity score is a useful indicator of micronutrient intake in non-breast-feeding Filipino children. J Nutr 137, 472-477.

46. Steyn N, Nel J, Nantel G et al. (2006) Food variety and dietary diversity scores in children: are they good indicators of dietary adequacy? Public Health Nutr 9, 644-650.

47. Minten B \& Stifel D (2015) Market Access, Welfare, and Nutrition: Evidence from Ethiopia. Ethiopia Strategy Support Program (ESSP) Working Paper no. 77. Washington, DC and Addis Ababa: International Food Policy Research Institute, IFPRI-ESSP Addis Ababa and Ethiopian Development Research Institute.

48. Hoddinott J, Headey D \& Dereje M (2015) Cows, missing milk markets and nutrition in rural Ethiopia. J Dev Stud 51, 958-975.

49. Ruel MT \& Alderman H (2013) Nutrition-sensitive interventions and programmes: how can they help to accelerate progress in improving maternal and child nutrition? Lancet 382, 536-551.

50. Masset E, Haddad L, Cornelius A et al. (2012) Effectiveness of agricultural interventions that aim to improve nutritional status of children: systematic review. BMJ 344, d8222.

51. Berti PR, Krasevec J \& FitzGerald S (2004) A review of the effectiveness of agriculture interventions in improving nutrition outcomes. Public Health Nutr 7, 599-609.

52. Vaitla B, Devereux S \& Swan SH (2009) Seasonal hunger: a neglected problem with proven solutions. PLOS Med 6, e1000101.

53. Central Statistical Agency of Ethiopia \& World Bank (2013) Ethiopia Rural Socioeconomic Survey (ERSS) Survey Report. Addis Ababa: CSA and World Bank.

54. Bachewe F, Berhane G, Hirvonen K et al. (2014) Feed the Future (FtF) of Ethiopia - Baseline Report 2013. Addis Ababa: Ethiopia Strategy Support Program and International Food Policy Research Institute. 